\title{
EPILEPSY IN CHILDHOOD: \\ Classification and Treatment
}

\author{
Malcolm MacGregor, M.D., F.R.C.P. \\ Consulting Paediatrician, South Warvickshire Hospital Group
}

\begin{abstract}
Aвоuт four per thousand children in the general population suffer from continuing fits, and of these the greatest number begin before three years old. This is therefore one of the conditions which all practitioners will encounter with fair frequency, and of all the common symptoms of childhood disease, fits carry the heaviest overtones of alarm and dread to parents. Diagnosis and management is in most cases simple, but every once in a while the doctor in pursuit of this symptom is led into a diagnostic labyrinth from which the biochemical and other resources of a hospital are required to rescue him.
\end{abstract}

\section{Classification}

A considerable proportion of childhood fits are the direct result of accompanying disease-head injury, meningitis, poisons, renal disease and so forth, and others occur in association with evident mental deficiency. These secondary epilepsies I propose for the moment to ignore, and to present to you instead a classification of those types of fit which occur without manifest disease. It is one theme of this morning's discussion that the EEG is of considerable value in indicating the type, and often therefore also the prognosis and treatment, of fits in childhood, and so you will not be surprised to find that my categories are founded upon EEG patterns fairly distinctive of each.

I. Febrile convulsions.-These are age-specific, selflimited, familial and benign. The EEG is generally normal. One must distinguish, in order to keep this group well-defined, those examples of fits of other types which begin fortuitously in relation to fever within this age group. The EEG pattern will often serve to distinguish them from benign febrile fits.

2. Infantile spasms. - Early onset, multiplicity, specific pattern of fit, typical EEG, sinister prognosis for mental development.

3. Central, or centrencephalic, epilepsy. - This group of patients is characterized by EEG tracings that show bilaterally synchronous activity, probably originating within the brain-stem. There is often a genetic factor to be traced in such families, and the outlook in general is good, both for frequency of fits and for response to treatment. Most petit $\mathrm{mal}$ is of this type, as well as many cases of generalized convulsions.

A special caveat exists for families in whom convulsions of this type start within the first year of life. These carry a risk of sudden death in the attack.
4. Cortical epilepsy.-This type of patient is about twice as frequent as the last group. They exhibit a wide range of clinical types without genetic or familial features, are difficult to control with drugs and are to be accompanied by disturbances of behaviour, whigh may be gross. The fits may be numerous, and aze characterized in the EEG by focal changes, most frequently in the temporal lobes. The focal lesions whic seem to excite fits in these cases are not fully understood. Asphyxial lesions of perinatal origin, small hæmorrhages or inflammatory scars, as well as congenital anatomical lesions are found. It is also thought that fits themselves can cause permanent vascular lesions in the temporal cortex, and so start off a perpetuating cycle of focal fits. Hence the importance of controlling fits, and partict larly of avoiding status epilepticus.

\section{Treatment}

Parents should always know the names and dosages of drugs in use for their child. They not be shielded from the word 'epilepsy', which be explained as a condition of excessive activit of a part of the brain. Parental fears of the attagk itself, or of its effect on intelligence and behaviougt, or of the effect of drugs on the personality, must discussed and alleviated. In general it is better run slight risks than to over-restrict such childrea. Solitary swimming, cycling or climbing are probably all that need be debarred.

The commonest mistake in drug treatment underdosage. Each drug or combination of drugs should be worked up to the maximum dose advised for the age before abandoning it as effective. More than two drugs in combination afe

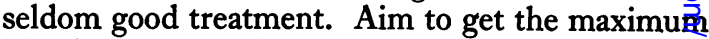
blood levels at the time when, in a particular child, fits are most frequent.

\section{Febrile convulsions}

No treatment for a single fit. If repeated, use phenळ barbitone and continue for two years or until the famidy pattern of convulsive behaviour makes it seem safe stop.

\section{Infantile spasms}

Very resistant to treatment. Phenobarbitone and steroid often give best control and steroid can be give until the EEG improves.

\section{Central epilepsy}

For petit mal phensuccidine is first choice. Acetazol mide (Diamox) and amphetamine are sometimes effectiof.

Troxidone very effective but more toxic. 
For grand mal phenobarbitone and phenytoin are drugs of choice, separately or in combination.

\section{Cortical epilepsy}

If phenobarbitone and phenytoin do not work, try primidone, alone or in combination. Librium may help the emotionally disturbed child with fits and may reduce fits too.

Various other little-used anticonvulsants owe their retention in the pharmacopoiea to occasional success with this group-drugs such as phenurone, gemonil, nydrane and (lately) opsolit.

\section{Epiloia}

\section{CASES DEMONSTRATED}

I. Neil M.-Born 1956, now aged $7 \frac{1}{2}$ years.

Began convulsions at 4 months old and these required large doses of drugs, and even so were difficult to control. $\mathrm{He}$ is considerably retarded mentally. A sister died at 22 months old and epiloia was diagnosed at post mortem. Mrs. M. has adenoma sebaceum. A grandfather had epilepsy. There is a normal elder boy. Difficult to manage at home, but is now clean and dry and feeds himself. An X-ray skull shows early calcification of the brain.

Comment.-This disorder must not be forgotten, and when the facial rash is present, is easy to spot. Worth considering with strong family history of fits.

\section{Infantile Spasms plus Hypsarrhythmia}

2. Susan $W$.-Born 1962, now aged 20 months.

First child. One month premature, birth weight $5 \frac{1}{2}$ lbs. Failed to thrive and admitted to hospital where treated as underfeeding for several months. Did well but looked a little odd. At 6 months passed developmental test for age. At 8 months old began fits, 2 to 3 times a day. Stiff body first, then leans forwards, arms spread and whimpers. Chaotic hypsarrythmia EEG. Started prednisone one week from onset of fits. Reduced frequency and intensity of fits, but EEG no better six weeks later. Fits stopped after eight weeks. EEG normal at 12 weeks. Seemed then some 4 months behind developmentally. Head circumference small. Promising progress since.

Comment.-The unusual and fortunate case of infantile spasms who improves. Could early treatment with prednisone be responsible? It is likely that there will be some mental retardation.

\section{Television Epilepsy}

3. Linda F. -Born $195 \mathrm{I}$, now aged $12 \frac{1}{2}$ years.

Single fit at $\mathrm{I} I \frac{1}{2}$. Doing homework $\mathrm{I} \mathrm{ft}$. away from T.V. screen and it was flickering badly. Healthy childno convulsions previously or since, and no family history of any. EEG strong photo-convulsive response, but irregular bilaterally synchronous spikes were also seen at other times.

Comment. - A child with a cerebral dysrhythmia, in whom an attack was provoked by the strong photo stimulus of television flicker. Avoidance of the precipitating situation is all that is required.

\section{Sturge-Weber Syndrome}

4. Aileen I.-Born $195 \mathrm{I}$, now aged 12 years.

Pink nævus over right forehead, terminating at midline, noticed from birth. Convulsions started at 7 weeks old. By 3 years old, typical intracranial calcification, subjacent to the external nævus, was evident in an X-ray of skull. A left spastic hemiplegia and mental retardation were evident. Mental retardation severe enough to require schooling at a Training Centre. No longer has regular anticonvulsants but remains subject to convul- sions at infrequent intervals. Wears caliper on leg. (One other normal child.)

Comment.-A rare condition but recognizable on sight. Striking X-ray appearance.

\section{Petit Mal-Akinetic Drop Attacks}

5. Geoffrey $W$. - Born 1957 , now aged nearly 6 years. At about 1 year old, frequent otorrhœe. Kept appearing with bruises on the head and it was thought he was being carelessly managed at home. He broke his skull at least once-he would walk along and suddenly crash to the ground, injuring himself. Elder brother had uncontrollable epilepsy during preschool period, then it ceased. No drug treatment effective. Admission to hospital always caused attacks to depart. However, when 4 years old paroxysmal bursts of bilaterally synchronous wave and spike were seen in EEG. Headmistress at school has once observed him unconscious for a few seconds after a fall. More recently nocturnal attacks suggesting major convulsions have occurred.

Comment.-Illustrates the difficulty of making a certain diagnosis in some cases, especially when, as frequently, fits cease in hospital.

\section{Spontaneous Hypoglycæmia}

6. Paul I.-Born 1958, now aged $4 \frac{3}{4}$ years.

First convulsion at $2 \frac{3}{4}$ years-noticed then to have a low CSF sugar. No antecedent infection (though one other child had a few febrile convulsions). Past history of exchange transfusion at birth. Four months later a second convulsion. Blood sugar then $36 \mathrm{mg}$./ $100 \mathrm{ml}$. Dramatic return of consciousness with -intravenous glucose. Attack six months later-drowsy-gradual coma with sweating. Again revived by intravenous glucose. Demonstrated that starvation through the day would lead to hypoglycæmia. Mother taught to give intramuscular cortisone in case of need. No trouble till May this year, when he again went into coma in spite of intramuscular cortisone. In spite of all that is known about him he was allowed to remain unconscious for 2 hours before reaching hospital. Now given extra food at I I p.m. nightly; tends to get faint first thing in the morning, especially Sundays.

Comment.-If hypoglycæmia is the cause of the fits, it is glucose not anticonvulsant that is required. Every doctor should keep one ampoule of intravenous dextrose in his bag.

\section{Convulsions in Infancy-Bad Family History}

7. David S.-Born 1962, now aged 17 months.

A worrying patient, not because of his own fits, which have shown no unusual characters, but because of his family history. One of three children, the eldest of whom died in status epilepticus at 17 months. Father suffers from epilepsy, and his mother (David's grandmother) died of status epilepticus. A maternal uncle had convulsions in childhood, and maternal great grandfather may have been epileptic. With this background, David was given regular phenobarbitone from 3 months old, but had a major convulsion at the onset of gastroenteritis at 7 months old in spite of this. Another at 9 months in spite of an increased dose of phenobarbitone, but an EEG then showed a normal tracing - given phenytoin as well since then. Another convulsion 6 months ago. His head circumference is a little small for his age. A further EEG in August was normal.

Comment. - This is a severe case of presumably centrencephalic epilepsy. A risk of death from status in infancy is known to exist in such families, and the tragedy to the first child illustrates this. One speculates whether he would have had status had he not been maintained on regular anticonvulsants. It is unexpected that he should have a normal EEG. 